\title{
Visualizing Shame: Menstruation, Graphic Medicine, and the Discourse of Lycanthropy
}

\author{
Sathyaraj Venkatesan ${ }^{1}$ and Anu Mary Peter ${ }^{2}$ \\ ${ }^{1}$ Associate Professor, Department of Humanities and Social Sciences, National Institute of \\ Technology (NIT), Tiruchirappalli, India-620015. ORCID: oooo-0oo3-2138-1263. \\ Email: sathya@nitt.edu \\ ${ }^{2}$ Assistant Professor, School of Social Sciences and Languages, Vellore Institute of \\ Technology (VIT), Chennai, Tamil Nadu, India. Email: oooo-ooo1-6740-8252. \\ Email: anumary.peter@vit.ac.in
}

\begin{abstract}
Beyond its medical definition as a natural phenomenon concerning the female body, menstruation is a term that is overburdened with a plethora of distorted cultural and religious meanings. Through the centuries, the biological process of the monthly expulsion of non-pregnant women's uterus lining is popularly misunderstood as a profane activity. Despite the surplus of awareness measurements to educate masses about menstruation's biological underpinnings, societal negligence towards women's incapacitating experiential realities associated with menstruation continues even in the twenty-first century. Accordingly, Paula Knight's graphic medical memoir on infertility, titled The Facts of Life (2017), offers a distinctive perspective about menstruation through the creative deployment of the lycanthrope metaphor. By depicting her menstruating self as a lone werewolf, Knight offers a compelling representation of menstruating women's abysmal corporeal and cultural anxieties. By close reading relevant images from Knight's memoir and drawing theoretical insights from Victoria Louise Newton and Elizabeth El Refaie, this article analyses how graphic medicine necessitates a humane and non-stigmatizing approach to menstruation.
\end{abstract}

Keywords: Menstruation, Metaphor, Lycanthropy, Graphic medicine, Comics, Stigma.

\section{Introduction}

In stark contrast with its medical definition as a natural and normal phenomenon in the female body, a distorted understanding of menstruation steeped in silence, shame and stigma has survived through the centuries. Irrespective of the medical awareness given to people about menstrual etiquettes and personal hygiene, there is a pervasive societal negligence towards women's incapacitating experiential realities associated with menstruation. Accordingly, Paula Knight's The Facts of Life (2017), a graphic medical memoir of infertility offers a refreshing perspective about menstruation through the creative deployment of the lycanthrope metaphor. By depicting herself during menstruation as a werewolf, Knight attempts a dynamic delineation of the terrifying corporeal and cultural anxieties experienced by menstruating women. Knight's utilization of the lone werewolf metaphor not only provides a radically subjective understanding of menstruation as a stigmatized gendered experience but also reinforces the need for women's

(c) AesthetixMS 2020. This Open Access article is published under a Creative Commons Attribution Non-Commercial 4.o International License (http://creativecommons.org/licenses/by-nc/4.o/), which permits non-commercial re-use, distribution, and reproduction in any medium, provided the original work is properly cited. For citation use the DOI. For commercial re-use, please contact editor@rupkatha.com. 
acceptance as opposed to social ostracization during menstruation. By close reading relevant images from Knight's memoir and by drawing theoretical insights from Victoria Louise Newton and Elizabeth El Refaie, this article analyses some of the underexamined cultural overtones of menstruation. In so doing, an attempt is made to explore how graphic medicine necessitates a non-stigmatizing cultural treatment of menstruation as a mere biological process.

\section{Clinical and Cultural Perspectives of Menstruation}

The Mayo Clinic defines menstruation as a monthly process where "one of the ovaries releases an egg-a process called ovulation. At the same time, hormonal changes prepare the uterus for pregnancy. If ovulation takes place and the egg isn't fertilized, the lining of the uterus sheds through the vagina" ("Menstrual Cycle: What's Normal, What's Not" n.p). Unsurprisingly, social taboos about menstruation have been the subject of discussion throughout history since at least 500 B.C. Accordingly, the Book of Leviticus in the Old Testament states that menstruation made women physically and spiritually 'unclean' and contagious (Newton, 2016, p. 19). Similarly, the ancient Greek and Roman cultures believed that menstruating women had supernatural destructive powers (Dean-Jones 1994; Delaney et al. 1988), and eventually menstrual blood became synonymous with "shame, difference, castration, filth, reproductive power, disease, and death to the Other" (Miller, 2005, p. 289).

Even though myths associated with menstruation have waned since the early modern era, the aura of shame and stigma continues to shroud matters related to menstruation to the extent that it is still treated as an "unfortunate, unpleasant and distasteful subject to address" (Strange, 2000, p. 609). Consequently, a plethora of euphemisms, metaphors and slang terms gained currency which "not only provide a conversational way around a difficult topic [menstruation], but also helps to shape, and are shaped by, societal views of menstruation" (Newton, 2016, p. 133). Some of the popular expressions of menstruation related to time are 'period', 'monthly', 'monthly leak', and 'that time of the month.' Sometimes, menstruation is personified as a visitor using expressions like 'Aunt flo', and 'Aunt Jane'. Terms like 'code red', 'red flag', 'blood in the moon' and 'blood bath' also depict menstruation as a menace. In a similar vein, medical science is also guilty of perpetuating a language of decay and disorder in relation to menstruation as obvious in terms such as 'catamenial derangement', 'decline' and the 'breaking down and exfoliation of the decidua' (Strange, 2000, p. 610).

\section{Verbo-Visual Rhetoric of Graphic Medicine}

In spite of the strong sociocultural impediments, women articulated their subjective experiences of menstruation through autobiographical writings (Pentimento by Lillian Hellman, The Curse: Confronting the Last Taboo, Menstruation by Karen Houppert, Moonchild: A Celebration of Menstruation by Mary Ann Kenny). Since pain erodes the linguistic capabilities of the sufferer, representation of tormenting bodily experiences that "cannot be spoken as it is felt" requires the use of "alternative cognitive structures of the visual" (Hirsch 2004, 1211). Therefore, autobiographical writings on bodily experiences like menstruation are laden with linguistic/graphic facilitators such as verbal/visual/verbo-visual metaphors or symbols. According to Refaie (2019, p. 117), a verbo-visual metaphor is a "combination of a picture of a concrete element and a verbal message that create metaphorical meanings." Interestingly, verbo-visual metaphors are an integral part of life-writing because "when we experience our bodies as problematic, we tend to search for metaphors that can help us understand and express aspects of 
our physical self" (Refaie, 2019, p. 57). As such, metaphors tend to be an essential element in tackling prevalent cultural notions of corporeality because the quintessence of metaphor lies in "the capacity to extend the imagination into recognizing new possibilities" (Legowski \& Brownlee, 2001, p. 25).

In this context, it is worthwhile to discuss how graphic medicine nurtures sentience towards the experience of menstruation and rescripts the traditional cultural inscriptions through creative verbo-visual metaphors. Graphic medicine is a subset of the medium of comics consisting of verbo-visual narratives of experiences such as illness, disability, trauma and pain among others. Defined as "the intersection of comics and the discourse of healthcare," graphic medicine is formulated as a discourse to offer "a more inclusive perspective of medicine, illness, disability, caregiving, and being cared for" (Cherie, 2015, p. 2). Created by Ian Williams, a British physician and graphic novelist, the graphic medicine discourse gained popularity when Michael Green and Kimberly Myers introduced it in 2010 through a research article titled "Graphic Medicine: Use of Comics in Medical Education and Patient Care" (British Medical Journal 2010). Commenting on the increased attention that comics medium started gaining in health communications, Green and Myers observed that "some healthcare professionals-especially those working in public health, with young people, or with non-native speakers-have begun to use graphic stories for patient care and education. One reason this practice is not more widespread is probably because most doctors have not considered its merits. We believe that graphic stories have an important role in patient care, medical education, and the social critique of the medical profession" (p. 574). With profound philosophical moorings in narrative medicine, graphic medicine strives to offer a better understanding of subjective experiences in healthcare through the medium of comics. Against the objective and reductionist approach of medical science towards health and illness, graphic medicine perpetuates the significance of having subjective and holistic understandings of illness experiences. Written mostly in the autobiographical style, graphic medicine narratives are repertories of subjective knowledge about illness/wellness experiences. Through various visual techniques and drawing styles, comics medium facilitates compelling portrayals of affective realities that are otherwise difficult to be articulated using words alone. Therefore, comics' structural features, together with the familiarity and simplicity of the medium, make graphic medicine a suitable way to communicate experiences of physical/psychological disruptions.

As opposed to illnesses that have visible effects on the body, the nuances of mental illnesses as well as the psychological impact of physical illnesses are often difficult to be communicated. Therefore, to depict the psychological terrains of illness experiences certain extralinguistic aids like metaphors are required in autobiographical narratives. Interestingly, graphic medicine unlike other conventional media of communication offers true-to-life representations of such experiences through using the unique capacities of comics medium. As Williams contends, comics can "actualize abstract elements of psychological suffering through "various devices, including metaphor, exaggeration, simile, emanata, and the manipulation of physical space and time-all important comics techniques, some of which are unique to the medium" (p. 125). As per its Greek origin, metaphor refers to shifting meaning from one word to another. In graphic medicine memoirs, the power of metaphors to capture the nuances of psychological experiences of pain/trauma is immense. Since metaphors are conceptual analogies, they can depict the highly subjective experience of an illness with the support of a pre-existing notion. When linguistic expressions are insufficient to convey the gravitas of psychological experiences, visual metaphors can effectuate meaningful communications between the artist and the reader. Thus, according to Ian Williams, "graphic medium facilitates a complex visual layering of subjective and objective experiences, bridging the gap between clinical facts and personal perception" (p. 64). The unified 
strength of verbal and visual media enables artists/sufferers in externalizing their cognitive/corporeal memories of suffering using visual metaphors, verbo-visual metaphors, and a wide range of drawing techniques.

By bringing an array of formal and rhetorical structures such as metaphors into play, graphic medicine "not only mirrors prevailing attitudes to, and advances in, healthcare, but also informs the way that illness and disease are culturally perceived" (Williams, 2013, p. 64). As Hirsch contends, using metaphors "the unspeakable may be better communicated emotionally and viscerally due to the relation of visuality to the experience" and that makes comics the most creative non-verbal medium of self-expression (p. 1211). Knight's graphic memoir utilizes comics medium as a sheltered space of self-expression where women can communicate their bodily truths on menstruation without being stigmatized. Knight's autobiographical graphic narrative, The Facts of Life deftly synthesizes the existing constellation of menstrual metaphors anchored on impurity, danger, alarm, monthly transformation, decay, disorder and profanity into one plausible metaphor drawn from the lycanthrope discourse. Knight's verbo-visual depiction of menstruation using the werewolf metaphor exemplifies Refaie's insight that metaphors in graphic illness narratives make "the apparently ordinary appear extraordinary, . . .[and] [thus] help readers understand the emotional, social and cultural impact of illness on sufferers" (2019, p. 87).

\section{The Facts of Life: Text and Context}

Published by Myriad Editions in 2017, The Facts of Life is a graphic memoir about Knight's attempt to challenge certain reductionist cultural ideologies that intertwine womanhood with motherhood. Drawn with highly creative brush strokes and infused with poignant streaks of philosophical wisdom, the memoir dismantles the popular assumption that maternity is the acme of muliebrity. Through Polly, the narrative avatar, Knight describes the pertinent challenges and stigma experienced by childless women. While the first half of the memoir portrays Polly's culturally conditioned childhood and early adolescence in the Northeast England during the late 1960s, the second half lays bare Polly's attempts to rescript the popular cultural (mis)understanding of marriage and childbearing as the supreme goals of a woman and unsettle the impervious association between a woman's value and her ability to procreate.

The major shift in the memoir happens when Polly struggles with infertility after meeting Jack, her partner. Polly and Jack deviate from the conventional pathway of parenthood when their consistent attempts for a baby fail. Like most other couples, they experience hopelessness and humiliation after several miscarriages. However, towards the end of the memoir, the couple reconciles with their bodily reality and shakes off the shroud of stigma and shame around infertility by gallantly taking up ecological nurturing as an alternative to biological motherhood. As a successful artist and a feminist, Polly relinquishes the prevalent notions of womanhood when she realizes that a woman can be complete even without giving birth to a child. In addition to infertility and (mo)therhood, several sub-themes like stigma around childlessness, pronatalism, the role of popular media and institutional forces in perpetuating cultural ideologies about womanhood, medical details of the treatment for infertility, among others are interlaced. Essentially, The Facts of Life does not try to untangle the vexed cultural knots of womanhood and motherhood but proposes the message that whether a woman is "childless or child-free," the meaning and purpose of her life is not nestled in her ability to reproduce (Knight, 2017, p. 227). 


\section{Menstruation as a Synonym of Shame}

Besides critically examining the socio-cultural pressure on women to be (re)productive, Knight offers unique visualizations of various struggles associated with femininity such as menstruation, pregnancy, and miscarriage among others. In utilizing the psychosomatic similitudes between menstruation and lycanthropy, Knight facilitates a renewed phenomenological understanding of the multi-dimensional otherness caused by menstruation. Through Polly, Knight demonstrates how information about menstruation from eclectic sources-parents, teachers, older siblings, peers, literature, and the media - shapes the relationship between an adolescent female and her maturing body (Koff \& Rierdan 1995). Here, Knight draws the readers' attention to the fact that instead of educating young girls about the prevalence of negative cultural notions of menstruation and ways to outlast them, only certain menstrual etiquettes are given significance.

During early adulthood, Polly's mother explains menstruation as a normal condition which "can feel a bit like tummy ache" with the discharge of a "special type of [blood] that nurtures the baby when it's in [the] womb" (Knight, 2017, p. 38). Likewise, at school, Polly receives a similar understanding about menstruation as a "perfectly normal, natural and healthy" phenomenon (Knight, 2017, p. 40). However, with the onset of menstruation, she realizes that beyond a "normal" biological condition it is a social taboo. The feeling that menstruation gave to Polly was far from what was taught by her mother, teachers and generations of women across the world. Polly's first experience of menstruation destabilized the notions of normalcy around menstruation and realigned it to shame, strangeness, secrecy and debility. Through a tier comprising three panels depicting the unspoken rule to keep menstruation a feminine secret, Polly describes how girls never talked about menstruation and were always cautious that they "never let boys hear it" just like her female relatives who hardly spoke about menstruation especially "in front of men!" (Knight, 2017, p. 42-43). The hesitancy of women to talk about menstruation made Polly believe that it is a shameful and invisible feminine ailment that ought to be guarded with silence and secrecy. Even though Polly was not asked by anyone to keep her menstruation a secret, she unintentionally became conscious of her otherness and refused to go out during those days (Knight, 2017, p. 41). Despite refraining from engaging in public articulations about menstruation, Polly began to feel ashamed of her body that has suddenly become leaky and out of control. As she reminiscences: "I did my utmost to keep it secret and [yet] felt embarrassed" (Knight, 2017, p. 42). Appropriately, Knight deploys the metaphorical trope of lycanthropy and equates the features of a werewolf with that of a menstruating female to visibilize how women are culturally desisted from openly expressing their experiential agonies that would redefine menstruation as an abnormal, ghoulish and embarrassing cultural condition.

\section{Menstruation and the Metaphor of Lycanthropy}

The term lycanthropy was originated from the tale of Lycaon, the Arcadian king in the Greek mythology who was cursed by Zeus to be a werewolf. As the myth goes, werewolves are cursed human beings who are susceptible to transfigure into wolves on full moon nights. The centrality of full moon denotes that the cursed human being is not in control, and the unstoppable metamorphosis is not induced by his/her desire. Paralleling a woman's monthly menstruation to that of a cursed man's lunar-influenced monthly metamorphosis into a werewolf, Knight deploys the popular lycanthrope metaphor to discuss the stigma surrounding menstruation. Accordingly, Polly is depicted as sitting under a leafless, and lifeless tree on the edge of a hill which is encircled by raging waves on a full moon night, ominously howling into the darkness like a cursed one 
about to morph into a werewolf with the moon rise. The larger than life dimension of the full moon against the negligible size of the protagonist and the surging waves ready to engulf her is a compelling visual note on the menstruating woman's lack of control over her bleeding body. Here, the subterranean undertones of lycanthropy and menstruation are clearly conveyed through two simple elements-the howl and the full moon.

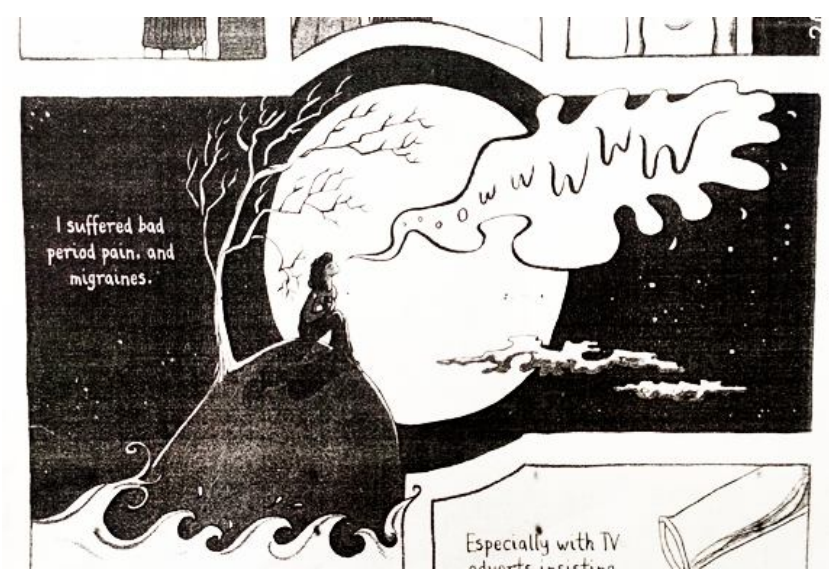

Figure 1. Knight, P. (2017). The Facts of Life. Brighton: Myriad Editions. (with permission)

Miller (p. 289) contends that "werewolves are linked to menstruation through their parallel reliance on the cycles of the moon and bodily transformations that blur the boundaries between animal and human, inside and outside." Accordingly, both werewolves and menstruating women share a monthly time frame of transition. Indescribable physical pain, psychological agony, helplessness, horror and an overbearing sense of impurity are some other common factors. Werewolves are castigated from society for their otherness and viciousness, and they typically abscond to clandestine wildernesses just before their lunar-induced shapeshifting. Similarly, the preconceived cultural notions of uncleanness associated with menstruation quarantines women from society during their menstruation, and menstruating women often undergo social isolation out of the fear of being stigmatized in public. Thus, a host of malicious notions about menstruation as a state of jeopardy, putrefaction, impurity or distress are crystallized in the lycanthrope metaphor; and therefore, Knight uses it to show menstruation as an excruciating transformation into an 'other' which completely challenges the feminine normalcy.

In The Second Sex, Simone de Beauvoir (p. 354) observes that menstruation can "inspire horror in the adolescent girl because they throw her into an inferior defective category. This sense of being declassed will weigh heavily upon her." As such, Polly's posture reflects her angst, watchfulness, secrecy, and all that are not natural correlates of the menstrual experience as per the clinical explanation. Even though Polly condenses her agony into a single sentence: "I suffered bad period pain and migraines", the visual metaphor conjures her overwhelming pain that could not be verbalized. Along with her posture and gestures, the use of emanatas and an onomatopoeic inscription of her howl emphasize the appropriateness of comics medium in effectively depicting the fine aspects of psychosomatic sufferings. According to Elaine Scarry (p. 4), "pain does not simply resist language but actively destroys it, bringing about an immediate reversion to a state anterior to language, to the sounds and cries a human being makes before language is learned." Read against such a background, the depiction of Polly's howl is a realistic and forceful articulation of her physical and psychological distress caused by menstrual pain, social stigma and othering. The ambience of horror created through darkness and raging waves is further enhanced by the full moon and the waves of blood emanating from the lower panel. Here, Polly ruminates 
on the unhealthy culture of secrecy about menstruation thus: "for something that was supposedly natural, normal and healthy, the world seemed intent on concealing the existence of periods. This did nothing to make me feel at ease with my own blood" (Knight, 2017, p. 42). Here, Knight adds another dimension to Polly's excruciating experience where she feels that she would drown in her menstrual blood. Therefore, it is evident that Polly's howl also doubles up as a distress call and a heart-wrenching cry for help. Nailing down the apathetic disposition of society towards menstruating women, Knight vehemently criticizes that the stigma and silence around menstruation not only disrupts the menstruating women's normal relationship with others but also with themselves. Simultaneously, the violent waves of blood could also be a graphiation of Polly's hormone fluctuation as well as her bleeding uterus. The bloody waves, and darkness along with the full moon can also be seen as a fine depiction of 'blood in the moon', a popular metaphor of menstruation. Apparently, though menstruation is not scientifically related to the lunar cycle, there is an etymological correlation between menstruation and the moon. The word 'menstruation' comes from the Latin word 'mensis' which means 'month' and it is related to the Greek word 'mene' meaning 'moon'. Further, the solitary tree on the hill is suggestive of Knight's social isolation and the lack of leaves depicts her psychological withering due to physical pain and psychological duress. In essence, by overtly tethering female pubescence with the mythological creature such as the werewolf, Knight poignantly depicts Polly's metaphorical transformation into a monstrous other during menstruation.

\section{Coda}

Equating a woman's psychological suffering to that of a victim's transformation to a werewolf, the memoir brings together both biology and mythology to critique the cultural negligence to the pertinent sufferings of menstruating women. Knight's lycanthrope metaphor is a daring articulation of the cultural silencing and shaming experienced by menstruating women and it embodies the deep-rooted anxieties of menstruating women about their cultural characterization as monstrous others. In comparing menstruation with lycanthropy, Knight also interrogates the cultural status of menstruation as a taboo that denigrates women as unclean which in turn ostracize them from the mainstream. Interestingly, Knight's depiction of menstruation using the language of comics brings together women across the world in acknowledging how different an experience is menstruation from what is popularly taught and believed to be. The memoir joins the array of graphic medicine narratives in expressing the voices of the marginalized by asking the society how long its menstruating women should be mutely howling away their pains in imagined wildernesses as the popular notions of menstruation are culturally glass-sealed by shame. Necessarily, through graphic medicine, the author behests for a realistic depiction of menstruation as an agonizing experience of ignominy, and that young females should be educated about practical ways to manage it, if it is impossible to rewire the cultural notions of menstruation as a taboo.

\section{References}

Czerwiec, M. K., Williams, I, Squier, S. M., Green, M. J., Myers, K. R., and Smith, S. T. (2015). Graphic medicine manifesto. Pen State University Press.

De Beauvoir, S. (1952). The second sex. Vintage. 
Dean-Jones, L. (1994). Women's Bodies in classical Greek science. Clarendon Press.

Delaney, J., Lupton, J. M., and Toth, E. (1988). The curse: A cultural history of menstruation. University of Illinois Press.

Green, M. J., \& Myers, K. R. (2010). Graphic medicine: Use of comics in medical education and patient care. British Medical Journal, 340(7746), 574.

Hirsch, M. (2004). Editor's column: Collateral damage. PMLA 119 (5), 1209-1215.

Knight, P. (2017). The facts of life. Myriad Editions.

Koff, E., \& Rierdan, J. (1995). Preparing girls for menstruation: Recommendations from adolescent girls."Adolescence 30(120), 795-812.

Legowski, T. \& Brownlee, K. (2001). Working with metaphor in narrative therapy." Journal of Family Psychotherapy 12(1): 19-28.

Mayo Clinic. (2006). "Menstrual cycle: What's normal, what's not." Available at https://www.mayoclinic.org/ healthy-ifestyle/womens-health/indepth/menstrual-cycle/art 20047186, accessed February 16, 2019).

Miller, A. (2005). 'The hair that wasn't there before:' Demystifying monstrosity and menstruation in ginger snaps and ginger snaps unleashed." Western Folklore Summer/Fall 281-303.

Newton, V. L. (2016). Everyday discourses of menstruation. Palgrave Macmillan.

Refaie, E. E. (2014). Looking on the dark and bright side: Creative metaphors of depression in two graphic memoirs. Auto/Biography Studies 29 (1): 149-174.

Refaie, E. E. (2019). Visual metaphor and embodiment in graphic illness narratives. Oxford University Press.

Scarry, E. (1985). The body in pain: The making and unmaking of the world. Oxford University Press.

Strange, J. M. (2000). Menstrual fictions: Languages of medicine and menstruation, c. 1850-1930. Women's History Review 9(3): 607-628.

Williams, I. C. M. (2013). Graphic medicine: The portrayal of illness in underground and autobiographical comics in Medicine, health and the arts, ed. by Bates, V., Bleakly, A., and Goodman, S. Routledge, 76-96.

Williams, I. (2015). Comics and the iconography of illness In Graphic medicine manifesto, ed. by Czerwiec, M. K, et al., Pen State University Press, 115-142.

Dr. Sathyaraj Venkatesan is currently an Associate Professor of English at the National Institute of Technology (NIT) Trichy. His research concentrates on literary health humanities, global health humanities, comics studies, and graphic medicine. He has authored over eighty-five publications and five books that span African American literature, Health Humanities, Graphic Medicine, Film studies, and other literary and cultural studies disciplines. His recent co-authored book is Gender, Eating Disorders, and Graphic Medicine (Routledge 2020).

Dr. Anu Mary Peter is an Assistant Professor in the Department of English, School of Social Sciences and Languages, Vellore Institute of Technology, Chennai, Tamil Nadu, India. She received her doctoral degree from the National Institute of Technology, Trichy where she was a Jawaharlal Nehru Doctoral Research Fellow. Her research interests include graphic medicine, comics, and gender studies. She is the author of My Impossible Highway (Partridge 2015) and Gender, Eating Disorders, and Graphic Medicine (Routledge 2020). 